\title{
Evaluation of Radiation Dose Received by Premature Neonates Admitted to Neonatal Intensive Care Unit
}

\author{
Mohmmadreza Aramesh ${ }^{\mathrm{a}}$, Kobra Aria Zanganeh ${ }^{\mathrm{a}}$, Masoud Dehdashtian ${ }^{\mathrm{a}}$, \\ Arash Malekiana ${ }^{\mathrm{a}}$ Jafar Fatahiasl ${ }^{\mathrm{b}, \mathrm{c}}$
}

\begin{abstract}
Background: This study aimed to evaluate the radiation dose received by premature neonates using diagnostic radiographies.

Methods: This cross-sectional study was conducted on 116 premature neonates with gestational age from 25 to 37 weeks; with the diagnosis of neonatal respiratory distress syndrome (NRDS) and tachypnea, they were admitted to a neonatal intensive care unit (NICU) at Ahvaz Imam Khomeini Hospital in 2015. For assessing the dose received, the model GR-200 thermoluminescent dosimeter (TLD) was used. For each premature neonate under radiation, three TLDs separately (one for each) were placed on surfaces of Ch1, T1, and G1 (chest, thyroid, and gonad of first newborn, respectively). Moreover, for the adjacent neonate at a distance of $60-100 \mathrm{~cm}$, two TLDs were laid in the surfaces of T2 and G2 (thyroid and gonad of second newborn, respectively). The dose received by TLDs for any baby and the adjacent neonate under the entrance surface dose (ESD) was estimated.
\end{abstract}

Results: The mean of neonates' weight under study was $1,950.78 \pm$ 484.9 g. During the hospitalization period, minimum one and maximum three radiographies were done for any premature neonate. The doses received in the premature neonates to Ch1, T1 and G1 were $0.08 \pm 0.01,0.06 \pm 0.01$, and $0.05 \pm 0.01 \mathrm{mSv}$, respectively and for adjacent infants for T2 and G2 were $0.003 \pm 0.001$ and $0.002 \pm 0.0009$ $\mathrm{mSv}$, respectively.

Conclusions: In the study, radiation dose received by organs at risk of premature neonates was lower than the international criteria and standards, therefore, also due to the lack of radiation damage threshold, to limit collimator, and the use of the proper filtration, kilovoltage and time during radiography of premature neonates are recommended.

Keywords: Entrance surface dose; Radiation; NICU; Received dose

Manuscript accepted for publication November 11, 2016

aDepartment of Neonatal Intensive Care Unit, Imam Khomeini Hospital, Ahvaz Jundishapur University of Medical Sciences, Ahvaz, Iran

bepartment of Radiology Technology, School of Paramedicine, Ahvaz Jundishapur University of Medical Sciences, Ahvaz, Iran

${ }^{\mathrm{c} C}$ Corresponding Author: Jafar Fatahiasl, Department of Radiology Technology, School of Paramedicine, Ahvaz Jundishapur University of Medical Sciences, Ahvaz, Iran. Email: Fatahi.j49@gmail.com

doi: https://doi.org/10.14740/jocmr2796w

\section{Introduction}

Recently, the concerns have increased about long-term effects of radiation exposure in neonates. Side effects of excessive intake threshold X-ray include cataract and skin injuries; however, its most important complication is the increased risk of hematologic and mass malignancies [1]. The risk, though the poor, gets more with the increased dose of exposure during the life. Since the tissues of children up to 10 times more than adults are sensitive to radiation, the risk is higher in children [2].

Neonates with low birth weight have a risk of the various medical and surgical issues; for this reason, numerous cases of diagnostic radiography may occur for them during a short period [3]. Plain radiographs include frequently thoracic, abdomen and sometimes the spine [4], which small size of the premature infants makes cause that a major part of their body is placed in the background of radiography; for this cause, they receive a higher effective dose compared to the adult [5]. Today, we know that there are a lot of proliferations and tissue differentiations during fetal growth and early childhood, and the proliferating cells are more prone to cancer induction [6]. In the neonatal intensive care unit (NICU), many neonates are kept in a large room, and this is a cause for that all the adjacent neonates are to be exposed to radiation for each request for a portable radiology image scan [7]. The aim of this study was to evaluate doses received by premature infants hospitalized in NICU of this hospital because of frequent diagnostic radiography during hospitalization.

\section{Materials and Methods}

\section{Study design and population}

This descriptive-analytical and cross-sectional study was conducted on 116 premature infants with neonatal respiratory distress syndrome (NRDS) and tachypnea hospitalized in the NICU ward in Ahvaz Imam Khomeini Hospital during 2015. A sample of 116 infants was randomly selected from among newborns admitted to NICU, regardless of the type of disease, gender and birth weight. Gestational age of infants at the birth was between 25 and 37 weeks. During the period of hospitalization for any premature neonate, at least one and a maximum of three radiographies were done. 
Table 1. Demographic and Mean Received Dose by Different Organs in Study's Premature

\begin{tabular}{lll}
\hline Variable & Mean \pm SD or n (\%) & Min. - Max. \\
\hline Male & $34(29.3)$ & - \\
Female & $82(70.7)$ & - \\
Gestational age (weeks) & $31.9 \pm 2.3$ & $26.0-36.0$ \\
Newborn's weight (g) & $1950.78 \pm 484.9$ & $800-3100$ \\
Newborn's height (cm) & $43.60 \pm 3.7$ & $34-50$ \\
Number of graphs & & \\
$\quad 1$ & $58(50.0)$ & - \\
\multicolumn{1}{c}{2} & $54(46.6)$ & - \\
$\quad 3$ & $4(3.4)$ & - \\
Distance between TLD and radiography film (cm) & $5.28 \pm 0.43$ & $3.5-6.0$ \\
Voltage (kVp) & $41.60 \pm 1.7$ & $34-48$ \\
Distance (cm) & $98.36 \pm 2.53$ & $90-100$ \\
T1 (mSv) & $0.06 \pm 0.01$ & $0.000-0.084$ \\
Ch1 (mSv) & $0.08 \pm 0.01$ & $0.046-0.111$ \\
G1(mSv) & $0.05 \pm 0.01$ & $0.016-0.07$ \\
T2 (mSv) & $0.003 \pm 0.001$ & $0.002-0.007$ \\
G2 (mSv) & $0.002 \pm 0.0009$ & $0.005-0.01$ \\
\hline
\end{tabular}

T1: thyroid of first newborn; Ch1: chest of first new born; G1: gonad of first newborn; T2: thyroid of second newborn; G2: gonad of second newborn.

\section{Inclusion criteria}

In this study, inclusion criteria included: 1) being premature infant; 2) suffering from NRDS and tachypnea; and 3) hospitalization in the NICU ward in Ahvaz Imam Khomeini Hospital during 2015.

In this study, to evaluate the dose received by patients, entrance surface dose (ESD) due to the diagnostic radiography of the thermoluminescent dosimeter (TLD) model GR-200 (Radiation Dosimetry TLD, HangzhouFreq-Electronic Control Technology Ltd, China), equivalent to the soft tissues of the body, was used.

For each infant under radiation, three TLDs were placed, one on the surface of Ch1 (chest of first newborn), and one on the surface of T1 (thyroid of first newborn) and one on the surface of G1 (gonads of first newborn). In addition, for adjacent newborn, two TLDs were laid on the surface of T2 (thyroid of second newborn) and G2 (gonads of second newborn) at a distance of $60-100 \mathrm{~cm}$. Estimation of the TLD dose received was calculated for both patients under the term ESD. At first, after purchase, TLDs were calibrated by the Atomic Energy Organization of Iran (AEOI) in the Secondary Standard Dosimetry Laboratory (SSDL) department and their calibration coefficient was calculated; then for readings, the TLD-reader device was used (Harshaw model, ThermoScientific ${ }^{\mathrm{TM}}$ Harshaw TLD model 3500 Automatic Reader, Thermo Fisher Scientific, USA) (all radiographs were done by a portable digital device, known as -30-XM (CR-AGFA, Belgium). Furthermore, quality control was made for the device by the supporting-related company with a license issued by AEOI. According to the number of X-rays and the estimation of ESD for each patient, the dose received was compared with a maximum effective dose permitted by the International Commission on Radiation Units and Measurements (ICRU).

On the other hand, at a distance of 60 and $100 \mathrm{~cm}$, the dose scattered from the adjacent patient, who was not under the direct influence of ray, was calculated, as well. Variables such as the pregnancy age, duration of hospitalization, weight, gender, number of X-rays, a distance with the adjacent infant at a distance of $60-100 \mathrm{~cm}$, and the amount of radiation received doses in Ch1 areas, T1 and G1 were recorded for every infant.

Statistical analysis was done using SPSS version 22. Quantitative variables were summarized as mean and standard deviation and qualitative variables were summarized as frequency and frequency percentage. The correlation between variables such as gestational age and the neonate's weight with the amount of beam dose in areas of T1, G1, and Ch1 was considered with the help of the Pearson's correlation coefficient with a significance level less than 0.05 . For adjusting confounding variables, the linear regression model was used.

\section{Results}

In total, 116 infants admitted to NICU with a mean gestational age of $31 \pm 2.3$ weeks and the age range of 25 - 37 weeks were analyzed. The average duration of hospitalization was $5.19 \pm$ 11.97 days (range: 3 - 25 days).

Table 1 shows demographic and radiographic profile in the study. In general, of 116 neonates, 34 (29.3\%) were female 
Table 2. The Pearson's Correlation Between the Variables of the Pregnancy Age at Birth and Baby's Weight With the Amount of Radiation Dose Received in Premature Infants Under Study

\begin{tabular}{llllll}
\hline Variable & T1 & Ch1 & G1 & T2 & G2 \\
\hline $\begin{array}{c}\text { Gestational age } \\
\quad \text { r }\end{array}$ & -0.200 & -0.424 & -0.623 & -0.108 & -0.196 \\
$\quad \begin{array}{l}\text { P-value } \\
\text { Newborn's weight }\end{array}$ & 0.032 & $<0.001$ & $<0.001$ & 0.247 & 0.035 \\
$\quad$ r & -0.209 & -0.361 & 0.573 & -0.101 & -0.135 \\
P-value & 0.024 & $<0.001$ & $<0.001$ & 0.279 & 0.149 \\
\hline
\end{tabular}

T1: thyroid of first newborn; Ch1: chest of first new born; G1: gonad of first newborn; T2: thyroid of second newborn; G2: gonad of second newborn.

and $82(70.7 \%)$ were male. A minimum of one graph and a maximum of three graphs were done for the neonates during hospitalization. Of 116 patients, $58(50 \%)$ received only one chest radiography, 54 patients $(64.6 \%)$ received two chest radiographies and only four patients (3.4\%) received three chest radiographies. The average weight of neonates was $1,950.78 \pm$ $484.9 \mathrm{~g}$ (min. - max.: 800 - 3,100 g). The average height of the neonates was $43.60 \pm 3.7 \mathrm{~cm}$ (min. - max.: $34-50 \mathrm{~cm})$. The average distance of the TLD with radiographic film was 5.28 $\pm 0.43 \mathrm{~cm}$ (min. - max.: $3.5-6 \mathrm{~cm}$ ). The average voltage was $41.60 \pm 1.7 \mathrm{mSv}$ (min. - max.: $34-48 \mathrm{mSv}$ ). The average distance between the newborns receiving $\mathrm{X}$-rays and newborns at the distance of $60-100 \mathrm{~cm}$ was $98.36 \pm 2.53 \mathrm{~cm}$ (min. - max.: $90-100 \mathrm{~cm})$.

The extents of the dose received in the premature infants for Ch1, T1 and G1 were $0.08 \pm 0.01,0.06 \pm 0.01$, and $0.05 \pm$ 0.01 , respectively and in adjacent infants for $\mathrm{T} 2$ and $\mathrm{G} 2$ were $0.001 \pm 0.003$ and $0.0009 \pm 0.002 \mathrm{mSv}$, respectively.

The Pearson's correlation between gestational age and dif- ferent organs of the first and adjacent newborns is presented in Table 2 . There were statistically reverse and significant correlations between gestational age and chest, gonad, and thyroid of first new born $(\mathrm{r}=-0.424, \mathrm{P}<0.001 ; \mathrm{r}=-0.623, \mathrm{P}<0.001 ; \mathrm{r}$ $=-0.209, \mathrm{P}<0.024 ; \mathrm{r}=-0.200, \mathrm{P}<0.032)$. There were reverse and significant correlation between gestational age and gonad $(\mathrm{r}=-0.196, \mathrm{P}<0.035)$, but there was not significant for thyroid of adjacent newborn $(\mathrm{r}=-0.108, \mathrm{P}<0.247)$.

There were reverse and significant correlation between newborn's weight and chest, gonad, and thyroid of first new born ( $\mathrm{r}=-0.361, \mathrm{P}<0.001 ; \mathrm{r}=-0.209, \mathrm{P}<0.024)$, but not reverse for thyroid $(\mathrm{r}=0.573, \mathrm{P}<0.0001)$. There were reverse but not statistically significant correlation between newborn's weight and gonad and thyroid for adjacent newborn $(r=-0.135$, $\mathrm{P}<0.149 ; \mathrm{r}=-0.101, \mathrm{P}<0.279)$.

Table 3 shows the correlation between received dose by thyroid, chest and gonad of the first newborn with gestational age and newborn's weight using linear regression. The results of regression model have shown a reverse statistically signifi-

Table 3. The Correlation Between Received Dose by T1, Ch1 and G1 With Variables of Gestational Age and Newborn Weight at the Birth Demonstrated by Linear Regression Model

\begin{tabular}{|c|c|c|c|c|c|}
\hline & \multicolumn{2}{|c|}{ Unstandardized coefficients } & \multirow{2}{*}{$\begin{array}{l}\text { Standardized } \\
\text { coefficients beta }\end{array}$} & \multirow{2}{*}{$\mathbf{t}$} & \multirow{2}{*}{ P-value } \\
\hline & B & Std. Error & & & \\
\hline \multicolumn{6}{|l|}{$\mathrm{T} 1$} \\
\hline Constant & 0.148 & 0.023 & - & 6.490 & $<0.001$ \\
\hline Gestational age & -0.003 & 0.001 & -0.544 & -2.695 & 0.008 \\
\hline Newborn's weight & $-3.638 \times 10^{-7}$ & 0.000 & -0.016 & -0.078 & 0.938 \\
\hline \multicolumn{6}{|l|}{ Ch1 } \\
\hline Constant & 0.16 & 0.024 & - & 6.581 & $<0.001$ \\
\hline Gestational age & -0.003 & 0.001 & -0.605 & -2.765 & 0.007 \\
\hline Newborn's weight & $4.462 \times 10^{-6}$ & 0.000 & 0.197 & 0.899 & 0.371 \\
\hline \multicolumn{6}{|l|}{ G1 } \\
\hline Constant & 0.148 & 0.022 & - & 6.644 & $<0.001$ \\
\hline Gestational age & -0.003 & 0.001 & -0.629 & -3.319 & 0.001 \\
\hline Newborn's weight & $1.783 \times 10^{-7}$ & 0.000 & 0.007 & 0.039 & 0.969 \\
\hline
\end{tabular}

T1: thyroid of first newborn; Ch1: chest of first newborn; G1: gonad of first newborn; T2: thyroid of second newborn; G2: gonad of second newborn. 


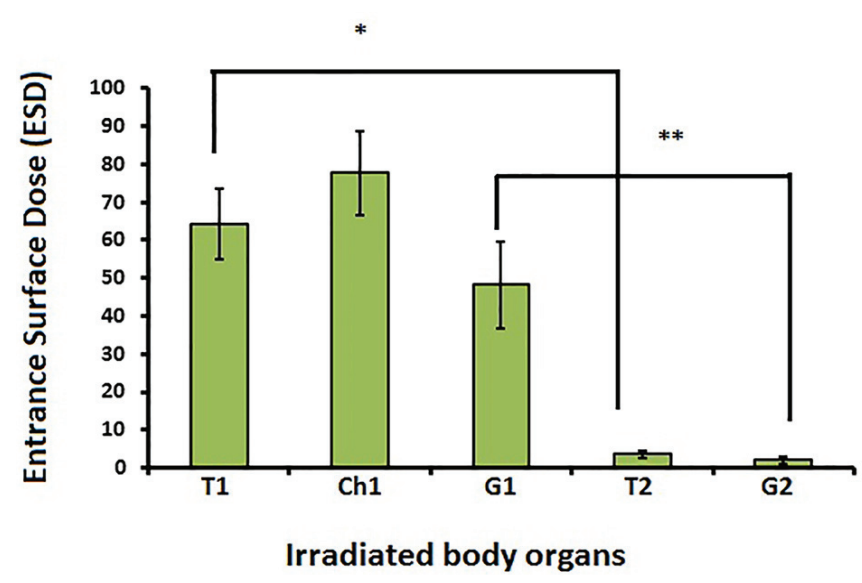

Figure 1. Comparison between mean ESD (mSv) in different infant's body organs. T1: thyroid of first newborn; Ch1: chest of first new born; G1: gonad of first newborn; T2: thyroid of second newborn; G2: gonad of second newborn. *Comparison of ESD between T1 and T2 $(\mathrm{P}<$ $0.001)$. ${ }^{* *}$ Comparison of ESD between $\mathrm{G} 1$ and $\mathrm{G} 2(\mathrm{P}<0.001)$. cant relation between gestational age and received radiation dose by thyroid, chest and gonad of first newborn, so that with every unit increase in gestational age, the average received dose by thyroid, chest and gonad of first newborn would be declined as $0.54,0.60$ and $0.63 \mathrm{mSv}$, respectively. No statistically significant correlation was observed between birth weight of first newborn and received radiation dose by thyroid, chest, and gonad. Figure 1 compares between mean ESD (mSv) in different infant's body organs. Figure 2 presents the comparison between mean ESD $(\mathrm{mSv})$ in different organs (chest, gonad, and thyroid) of first newborn according to newborn's weight groups (less than 1,500 g, between 1,500 and 2,500 $\mathrm{g}$ and more than $2,500 \mathrm{~g}$ ).

\section{Discussion}

This study investigated premature infants admitted to NICU with a birth weight range of $800-3,100 \mathrm{~g}$ and a birth age range of 25 - 37 weeks of gestation in terms of effective rates of re-
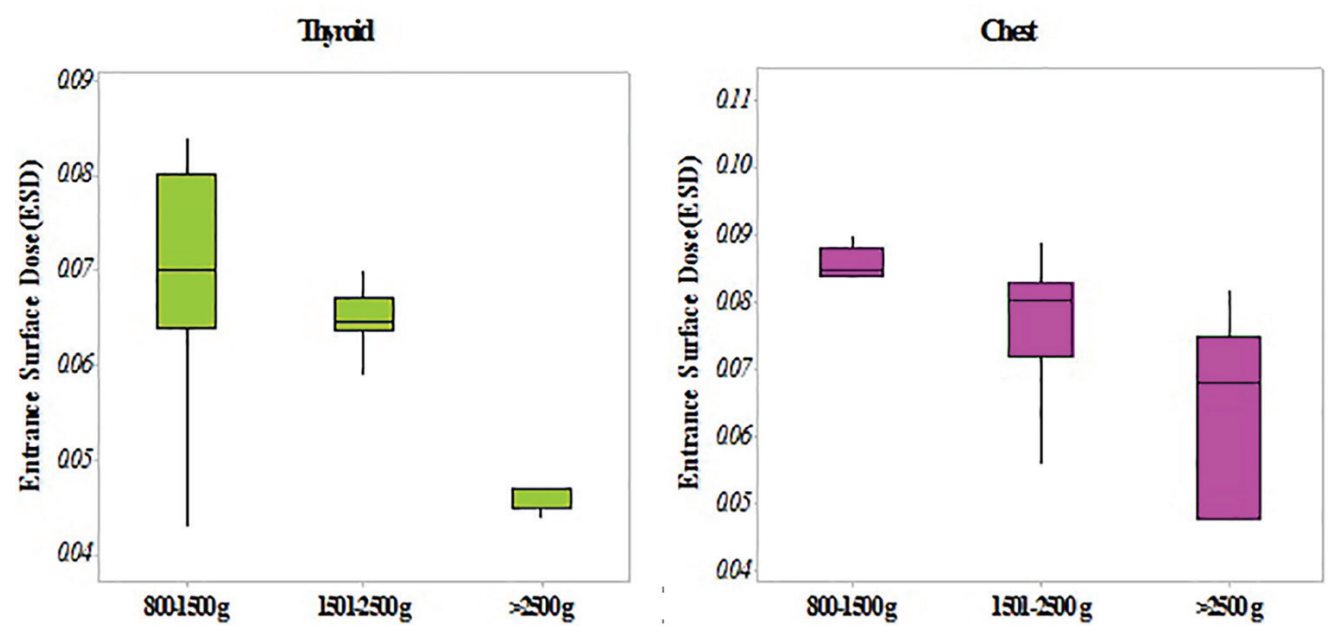

Gomad

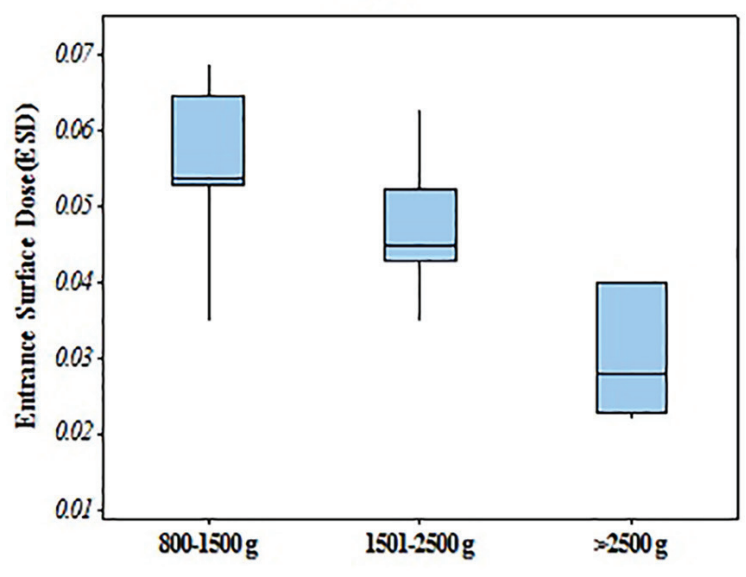

Figure 2. Comparison between mean ESD (mSv) in different organs (chest, gonad, and thyroid) of first newborn according to newborn's weight groups (less than 1,500 g, between 1,500 and 2,500 $\mathrm{g}$ and more than 2,500 g). The average received dose by all three organs reduced by increasing the infant's weight. 
ceiving radiography dose. During the period of hospitalization, at least one radiography and a maximum of three radiographies were done. Averages of dose received for the Ch1, T1 and G1 were $0.07,0.07$ and $0.1 \mathrm{mSv}$, respectively and for newborns at a distance of $60-100 \mathrm{~cm}$ for T1 and G1, they were 0.004 and $0.0019 \mathrm{mSv}$, respectively. Generally, the patient's dose depends on ESD, the sensitivity of organ and tissue under the radiation [8]. According to most studies, the amount of radiation dose to infants in the single radiation is low, but repeated radiography may cause a high cumulative dose [9].

Researchers have shown that there is a reverse relationship between radiosensitivity with age. Therefore, it is concluded that infants, especially premature infants, are more sensitive to radiation than adults. The amount of the ESD recommended by the European Commission on radiography of the infants' chest is $90 \mu \mathrm{Gy}$ equivalent with $0.08 \mathrm{mSv}$ and the amount recommended by the National Radiological Protection Board is 50 $\mu \mathrm{Gy}$ equal to $0.05 \mathrm{mSv}$ [10]. In addition, in accordance with the guidelines of the International Commission for Radiation Protection, the maximum amount of radiation permitted for babies is $1 \mathrm{mSv}$ [11]. ESD values in our study are a little less than this amount. Compared to other organs and body tissues, $\mathrm{G} 1$ has a higher tissue sensitivity, which can be $0.2 .0 \mathrm{mSv}$ [12]. Our findings showed that the rate of uptake in the G1 is a little less than the Ch1 and the T1. In their study in 2012, Toossi et al reported an ESD rate of $85.191 \mu \mathrm{G}$ in the infant's chest [13].

Furthermore, a significant reverse relationship was observed between gestational age and birth weight of newborns with the cumulative dose rate entered into the skin of the Ch1, $\mathrm{T} 1$ and G1. These findings are consistent with the previous studies $[4,8,14]$. In the current study, along with the increase in weight, an average of ESD is decreased. In contrast to our findings, in a study by Smans et al, neonatal weight has been divided into three groups (less than 1,000 g, 1,000 up to 2,500 $\mathrm{g}$ and over 2,500 $\mathrm{g}$ ). They observed that with the increase in weight, an average of ESD also is increased [15].

In addition, results achieved in the field of scattered beams have shown that the amount of scattered beams reached to infants is slight, but a minimum safe distance between incubators should be carefully seen [4]. A study by Oglar et al showed that when the distance of babies from each other is $2 \mathrm{~m}$, the amount of scattered beams reached to babies is low, but they recommend that this distance should be greater, due to the high radiosensitivity in neonates [7]. In the present study, the average radiation doses received by babies adjacent in a distance of $60-100 \mathrm{~cm}$ in the T2 and G2 were 0.004 and $0.0019 \mathrm{mSv}$. These data are consistent with the findings of the studies published by Olgar et al [7], Duetting et al [16] and Trinh et al [17]. Our results showed that in a univariate analysis, the correlation was observed between the variables such as gestation age, newborns weight and average received dose through the Ch1, T1 and G1. However, in the linear regression analysis, after adjusting the confounding variable, a reverse significant correlation was observed between the variables regarding gestation age and average received dose through the Ch1, T1 and G1. In spite of this, a significant correlation was not observed between the variables regarding newborns weight and average received dose through the Ch1, T1 and G1. A previous report by Atalabi et al showed there is no correlation between received dose and different age and weight of patients [18].

Our study has several limitations. This is a single-center study. The duration of the study is short. To get the general pattern of how to prescribe and perform radiography in NICU Department requires a study with more time.

\section{Conclusion}

The result of the study showed that radiation dose received by organs at risk of premature neonates was lower than the international criteria and standards; however, due to a lack of radioactive damage threshold, and for preventing the genetic damages, it is recommended that collimator be limited, and while using radiography of premature neonates, the appropriate filtration, kilovoltage and time be used.

\section{Acknowledgments}

This paper is issued from the thesis by Ariazanganeh. This study was financially supported by medical research grant number U-94031 from research deputy of Ahvaz of Ahvaz Jundishapur University of Medical Sciences; thereby, authors express thanks for the financial support.

\section{Conflicts of Interest}

None of the authors have any potential conflicts of interest associated with this study.

\section{References}

1. Berrington de Gonzalez A, Darby S. Risk of cancer from diagnostic X-rays: estimates for the UK and 14 other countries. Lancet. 2004;363(9406):345-351.

2. Hall P, Adami HO, Trichopoulos D, Pedersen NL, Lagiou P, Ekbom A, Ingvar M, et al. Effect of low doses of ionising radiation in infancy on cognitive function in adulthood: Swedish population based cohort study. BMJ. 2004;328(7430):19.

3. Puch-Kapst K, Juran R, Stoever B, Wauer RR. Radiation exposure in 212 very low and extremely low birth weight infants. Pediatrics. 2009;124(6):1556-1564.

4. Shahbazi-Gahrouei D, Nazem M, Sharbafchizadeh M, Jafarpishehfard MS. The Average of Cumulative Radiation Dose in Neonates in the Neonatal Surgery Ward Due to Diagnostic and Therapeutic Radiologic Procedures During the Admission Period. Journal of Isfahan Medical School. 2011;29(140).

5. Donadieu J, Zeghnoun A, Roudier C, Maccia C, Pirard $\mathrm{P}$, Andre C, Adamsbaum $\mathrm{C}$, et al. Cumulative effective doses delivered by radiographs to preterm infants in a neonatal intensive care unit. Pediatrics. 2006;117(3):882888.

6. Richardson RB. Past and revised risk estimates for cancer 
induced by irradiation and their influence on dose limits. Br J Radiol. 1990;63(748):235-245.

7. Olgar T, Onal E, Bor D, Okumus N, Atalay Y, Turkyilmaz $\mathrm{C}$, Ergenekon E, et al. Radiation exposure to premature infants in a neonatal intensive care unit in Turkey. Korean J Radiol. 2008;9(5):416-419.

8. Iyer NP, Baumann A, Rzeszotarski MS, Ferguson RD, Mhanna MJ. Radiation exposure in extremely low birth weight infants during their neonatal intensive care unit stay. World J Pediatr. 2013;9(2):175-178.

9. Sorop I, Dadulescu E. Assessment of entrance surface doses for newborn babies within an intensive care unit. Romanian Reports in Physics. 2011;63(2):401-410.

10. Chawla SC, Federman N, Zhang D, Nagata K, Nuthakki S, McNitt-Gray M, Boechat MI. Estimated cumulative radiation dose from $\mathrm{PET} / \mathrm{CT}$ in children with malignancies: a 5-year retrospective review. Pediatr Radiol. 2010;40(5):681-686.

11. Yu CC. Radiation safety in the neonatal intensive care unit: too little or too much concern? Pediatr Neonatol. 2010;51(6):311-319.

12. Commission CNS. Radiation doses 2015. Available from: http://nuclearsafety.gc.ca/eng/resources/radiation/intro- duction-to-radiation/radiation-doses.cfm.

13. Bahreyni Toossi MT, Malekzadeh M. Radiation dose to newborns in neonatal intensive care units. Iran J Radiol. 2012;9(3):145-149.

14. Vohr BR, Wright LL, Dusick AM, Perritt R, Poole WK, Tyson JE, Steichen JJ, et al. Center differences and outcomes of extremely low birth weight infants. Pediatrics. 2004;113(4):781-789.

15. Smans K, Struelens L, Smet M, Bosmans H, Vanhavere F. Patient dose in neonatal units. Radiat Prot Dosimetry. 2008;131(1):143-147.

16. Duetting T, Foerste B, Knoch T, Darge K, Troeger J. Radiation exposure during chest $\mathrm{X}$-ray examinations in a premature intensive care unit: phantom studies. Pediatr Radiol. 1999;29(3):158-162.

17. Trinh AM, Schoenfeld AH, Levin TL. Scatter radiation from chest radiographs: is there a risk to infants in a typical NICU? Pediatr Radiol. 2010;40(5):704-707.

18. Atalabi OM, BidemiI A, Adekanmi AJ, Samuel OA. Entrance surface dose from pediatric diagnostic x-ray examinations in a developing world setting: are we'ALARA rinciple'compliant? British Journal of Medicine and Medical Research. 2013;3(4):2288. 